\title{
Avaliação de estação de tratamento de esgoto com reator anaeróbio recebendo lodo de estação de tratamento de água Actiflo ${ }^{\circledR}$
}

\author{
Evaluation of wastewater treatment plant with anaerobic \\ reactor receiving sludge from water treatment plant Actiflo ${ }^{\circledR}$
}

Luiz Fernando Wagner ${ }^{1 *}\left(\mathbb{0}\right.$, Giovana Kátie Wiechetech² ${ }^{\oplus}$, Marcos Rogério Széliga²

\begin{abstract}
RESUMO
O objetivo deste trabalho foi analisar a disposição do lodo do decantador de uma estação de tratamento de água (ETA) com sedimentação lastreada por microareia $\left(\right.$ Actiflo ${ }^{\circledR}$ ) em uma estação de tratamento de esgoto (ETE) composta de upflow anaerobic sludge blanket (UASB) e lagoa de polimento, em Ponta Grossa, Paraná. A ETE Verde operou em condição estável, com uma vazão média afluente de 213,14 L.S.'. Os UASBs operaram com tempo de detenção hidráulica (TDH) de 9,9 horas, carga hidráulica volumétrica de 2,4 $\mathrm{m}^{3} \cdot \mathrm{m}^{-3} \cdot \mathrm{d}^{-1}$ e carga orgânica volumétrica (COV), em função da demanda química de oxigênio (DQO), variando entre 0,75 e 1,66 kgDQO. $\mathrm{m}^{-3} \cdot \mathrm{d}^{-1}$. A lagoa operou com TDH de 4,5 dias, com taxa de aplicação superficial variando entre 765 e 2.872 kgDQO.ha ${ }^{-1} \cdot \mathrm{d}^{-1}$ e COV variando entre 19 e 72 gDQO.m $\mathrm{m}^{-3} \cdot \mathrm{d}^{-1}$. A eficiência na remoção de DQO e sólidos suspensos totais (SST) foi mantida, mesmo com o lançamento do lodo da ETA. A eficiência da ETE variou entre 80 e 86\% para a remoção de DQO e entre 92 e 96\% para a remoção de SST. Concluiu-se que o lançamento na rede de esgotos é uma alternativa viável de disposição do lodo do decantador da ETA Actiflo ${ }^{\oplus}$.
\end{abstract}

Palavras-chave: lodo de estação de tratamento de água; Actiflo; estação de tratamento de esgoto; UASB.

\begin{abstract}
The objective of this paper was to analyze the disposal of decanter's sludge from a WTP with microsand ballasted sedimentation (Actiflo ${ }^{\circledR}$ ) in a WWTP containing UASB reactors and polishing pond, in Ponta Grossa - PR. The WWTP Verde operated in stable condition, with an average flow tributary of 213.14 L.S.'. The UASBS operated with HRT in 9.9 hours, VHL in $2.4 \mathrm{~m}^{3} \cdot \mathrm{m}^{-3} \cdot \mathrm{d}^{-1}$ and OLR ranging from 0.75 to $1.66 \mathrm{kgCOD} \cdot \mathrm{m}^{-3} \cdot \mathrm{d}^{-1}$. The polishing pond operated with HRT in 4.5 days and OLR ranging from 765 to $2872 \mathrm{kgCOD} \cdot \mathrm{ha}^{-1} \cdot \mathrm{d}^{-1}$, which corresponds from 19 to $72 \mathrm{gCOD} \cdot \mathrm{m}^{-3} \cdot \mathrm{d}^{-1}$. The efficiency of COD and TSS removal was maintained even with the release of WTP sludge. WWTP's efficiency ranged between $80 \%$ and $86 \%$ for COD removal and between $92 \%$ and $96 \%$ for TSS. It was concluded that the release in the sewage collection network is a viable alternative to disposal of the decanter's sludge from WTP Actiflo ${ }^{\circledR}$
\end{abstract}

Keywords: sludge of water treatment plant; Actiflo; wastewater treatment plant; UASB.

\section{INTRODUÇÃO}

O lodo é o principal resíduo gerado nas estações de tratamento de água (ETAs). Nas ETAs convencionais, o lodo é produzido principalmente nos decantadores, onde os flocos formados pela adição dos coagulantes (normalmente sais de alumínio ou de ferro) são separados da água pelo processo de sedimentação.

O volume médio de resíduos gerados diariamente nos decantadores das ETAs convencionais varia entre 0,1 e 3\% do volume total de água tratado na unidade (DI BERNARDO; DANTAS; VOLTAN, 2012).
Para as ETAs da região metropolitana de São Paulo, por exemplo, foi estimada uma produção de 106,1 t.dia ${ }^{-1}$ de lodo, em base seca, para o ano de 2003 (JANUÁRIO; FERREIRA FILHO, 2007). A Companhia de Saneamento do Paraná (SANEPAR) possui 176 ETAs operando no estado, com uma geração estimada de lodo para o ano de 2011 de 118 mil L.dia ${ }^{-1}$ (CARNEIRO; ANDREOLI, 2013).

Considerado pela Norma Brasileira (NBR) 10004:2004 (ABNT, 2004) como um resíduo não inerte e não perigoso, de classe II A, o lodo de ETA é caracterizado por possuir umidade superior a 95\% em 
volume (MARGUTI; FERREIRA FILHO; PIVELI, 2018), alto teor de cálcio, potássio e magnésio, além do ferro e alumínio provenientes do coagulante utilizado (ASADA et al., 2010).

A destinação adequada do lodo das ETAs, de forma economicamente viável e ambientalmente segura, tem sido um dos grandes desafios das companhias de abastecimento público de água do Brasil na atualidade, visto que o descarte desse resíduo in natura nos corpos d'água passou a ser considerado crime ambiental pela legislação brasileira a partir do final da década de 1990 (ACHON; BARROSO; CORDEIRO, 2013).

Dentre as alternativas de disposição de rejeitos de ETA que têm sido estudadas recentemente, destacam-se: disposição em aterro (JANUÁRIO; FERREIRA FILHO, 2007), aplicação controlada no solo (BITTENCOURT et al., 2012), fabricação de material cerâmico (SANTOS; MELO FILHO; MANZATO, 2018; WOLFF; SCHWABE; CONCEIÇÃO, 2015), aplicação em concreto (TAFAREL et al., 2016) e lançamento em sistemas de tratamento de esgotos (NAIR; AHAMMED, 2015; FERREIRA FILHO et al., 2013; MARGUTI; FERREIRA FILHO; PIVELI, 2018; SHARMA; THORNBERG; ANDERSEN, 2013).

O município de Ponta Grossa, no Paraná, possui duas ETAs: a ETA Pitangui, que utiliza o tratamento convencional, e a ETA Actiflo ${ }^{\circledR}$, que utiliza o tratamento com sedimentação lastreada por microareia, ambas operadas pela SANEPAR, concessionária do serviço público no município.

A sedimentação lastreada por microareia, ou Actiflo ${ }^{\circledR}$, é uma melhoria do processo de sedimentação floculenta que ocorre em uma ETA convencional. É um sistema de tratamento físico-químico de alto rendimento, que introduz partículas de microareia na etapa de coagulação, acelerando a formação e aumentando o tamanho e o peso dos flocos durante a etapa de floculação, o que proporciona uma clarificação da água muito mais rápida, durante a etapa de sedimentação (USEPA, 2003).

O lodo proveniente do decantador da ETA Actiflo ${ }^{\circledR}$ pode ser destinado à rede coletora de esgotos existente, a qual faz parte da bacia de esgotamento sanitário da estação de tratamento de esgoto (ETE) Verde, uma das dez estações de tratamento de efluentes do município, e a SANEPAR demonstrou interesse em estudar essa alternativa de disposição.

Dessa forma, o propósito deste trabalho foi analisar a alternativa de disposição do lodo da ETA Actiflo ${ }^{\circledR}$ na ETE Verde, via rede coletora de esgotos, de modo a avaliar a viabilidade dessa alternativa quanto ao impacto causado na eficiência do processo de tratamento da ETE, através dos dois principais parâmetros de controle do processo: demanda química de oxigênio (DQO) e sólidos suspensos totais (SST).

\section{METODOLOGIA}

A pesquisa foi desenvolvida na ETA Actiflo ${ }^{\circledR}$ e na ETE Verde, ambas de propriedade da SANEPAR, no município de Ponta Grossa, Paraná, nos anos de 2013 e 2014.
A ETA Actiflo ${ }^{\circledast}$ encontra-se operando desde o ano de 2009, tratando a água proveniente de duas captações superficiais, uma na Represa Alagados e a outra no Rio Pitangui, com vazão média aproximada de 480 L.s ${ }^{-1}$. A ETA utilizava cloreto de polialumínio (PAC) como coagulante, durante o período da pesquisa.

A água chega à ETA Actiflo ${ }^{\circledR}$ em um vertedor Parshall, onde recebe adição de coagulante, passa pelas câmaras de coagulação onde há adição de microareia e polímero catiônico, segue para a câmara de floculação e em seguida, para o decantador. No decantador, o material sedimentado é removido continuamente através de um raspador de fundo mecanizado e, posteriormente, é encaminhado a um hidrociclone para a separação da microareia, reutilizada no processo. O lodo resultante foi encaminhado à rede coletora de esgotos durante a realização da pesquisa.

Após encontrar a rede de esgotos, o lodo da ETA percorre aproximadamente 6,651 km até chegar à ETE Verde, com tempo de deslocamento estimado entre 1 e 2 horas. A ETE Verde é a maior ETE do município, operando com uma vazão média anual em torno de $210 \mathrm{~L} . \mathrm{s}^{-1}$ de esgoto doméstico.

A ETE Verde é constituída das seguintes unidades principais: sistema de gradeamento com limpeza manual e gradeamento mecanizado, com grades metálicas com espaçamento de 25 e $10 \mathrm{~mm}$, respectivamente; dois desarenadores ciclônicos com diâmetro de $4 \mathrm{~m}$, com forma cônica e fluxo em espiral, em que a velocidade média é mantida próxima a $0,3 \mathrm{~m} \cdot \mathrm{s}^{-1}$; vertedor Parshall com largura de garganta $\mathrm{w}=1$ ' e medidor de nível ultrassônico acoplado, que possibilita o registro contínuo da vazão de esgotos afluente à ETE; 4 reatores anaeróbios upflow anaerobic sludge blanket (UASB), tipo RALF módulo XVI, padrão SANEPAR, projetados para vazão média de $70 \mathrm{~L} \cdot \mathrm{s}^{-1} \mathrm{e}$ vazão máxima de $140 \mathrm{~L} . \mathrm{s}^{-1}$, com volume útil de $1.900 \mathrm{~m}^{3}$ cada um, interligados entre si; lagoa de polimento com $160 \mathrm{~m}$ de comprimento, $130 \mathrm{~m}$ de largura e 4,0 $\mathrm{m}$ de profundidade, de onde o efluente final tratado é encaminhado ao corpo receptor, o Rio Verde; e os leitos de secagem que, juntamente com a unidade de gerenciamento de lodo (UGL) e centrífuga do tipo “decanter”, fazem o desaguamento e a desinfecção do lodo.

À época da pesquisa, os RALFs operavam com tempo de detenção hidráulica (TDH) médio anual de 10,1 horas, carga hidráulica volumétrica (CHV) de $2,4 \mathrm{~m}^{3} \cdot \mathrm{m}^{-3} \cdot \mathrm{d}^{-1}$ e carga orgânica volumétrica (COV) aplicada de $0,76 \mathrm{kgDQO} \cdot \mathrm{m}^{-3} \cdot \mathrm{d}^{-1} \mathrm{e}$ a lagoa de polimento operava com TDH médio anual de 5 dias, taxa de aplicação superficial (TAS) de $890 \mathrm{kgDQO} \cdot \mathrm{ha}^{-1} \cdot \mathrm{d}^{-1}$ e COV aplicada de 23 gDQO.m $\mathrm{m}^{-3} \cdot \mathrm{d}^{-1}$.

A caracterização do lodo da ETA Actiflo ${ }^{\circledR}$ foi feita a partir de três amostras da água da descarga do decantador, sendo uma coletada no verão (dia 08/01/2013) e as outras duas no inverno (dias 08/07/2013 e 13/08/2013). Para efeito de comparação, também foram coletados os resíduos gerados nos decantadores da ETA Pitangui, na mesma data.

As análises dos parâmetros físico-químicos e microbiológicos foram realizadas em laboratório próprio da SANEPAR, na cidade de Curitiba, Paraná, e as análises de metais foram realizadas por um laboratório 
terceirizado da SANEPAR, também situado na cidade de Curitiba. Os parâmetros foram analisados segundo o Standard Methods for the Examination of Water and Wastewater (SMEWW) (APHA; AWWA; WPCF, 1998).

A vazão de descarte de lodo da ETA Actiflo ${ }^{\circledR}$ foi obtida a partir da variação de volume pelo tempo, medido em um dos poços de visita existentes no pátio da ETA, com diâmetro interno de $0,80 \mathrm{~m}$. Utilizando um sensor de nível ultrassônico marca Nivetec, modelo SPE 390, e um registrador eletrônico de sinais analógicos do tipo "data logger" portátil marca Novus, modelo LogBox-AA, foram efetuadas medições de variação de nível da lâmina líquida no poço de visita, nos dias 11/03/2014 (com tempo seco) e 25/03/2014 (com tempo chuvoso), sendo obtido o total de 67 registros de vazão.

Foi estabelecido o cronograma de escalonamento para o descarte do lodo da ETA, conforme apresentado no Quadro 1, variando o tempo de

Quadro 1 - Cronograma de descarte do lodo da estação de tratamento de água Actiflo ${ }^{\circledast}$.

\begin{tabular}{|c|c|c|c|c|c|c|c|c|c|}
\hline \multirow[t]{2}{*}{ Fase } & \multirow{2}{*}{ Período } & \multirow{2}{*}{$\begin{array}{l}\text { Início do } \\
\text { descarte } \\
\text { de lodo }\end{array}$} & \multirow{2}{*}{$\begin{array}{l}\text { Término do } \\
\text { descarte } \\
\text { de lodo }\end{array}$} & \multicolumn{6}{|c|}{$\begin{array}{l}\text { Tempo de descarte } \\
\text { contínuo (h) }\end{array}$} \\
\hline & & & & 4 & 8 & $\overline{12}$ & 16 & 20 & 24 \\
\hline 1 & $\begin{array}{l}\text { 10/03 a } \\
\text { 06/05/14 }\end{array}$ & $\begin{array}{c}\text { sem } \\
\text { descarte }\end{array}$ & $\begin{array}{c}\text { sem } \\
\text { descarte }\end{array}$ & & & & & & \\
\hline 2 & $\begin{array}{l}07 / 05 a \\
20 / 05 / 14\end{array}$ & $8 \mathrm{~h}$ & $12 \mathrm{~h}$ & $x$ & & & & & \\
\hline 3 & $\begin{array}{l}\text { 21/05 a } \\
\text { 03/06/14 }\end{array}$ & $8 \mathrm{~h}$ & $16 \mathrm{~h}$ & $x$ & $x$ & & & & \\
\hline 4 & $\begin{array}{l}04 / 06 \text { a } \\
17 / 06 / 14\end{array}$ & $8 \mathrm{~h}$ & $2 \mathrm{Oh}$ & $x$ & $x$ & $x$ & & & \\
\hline 5 & $\begin{array}{l}\text { 18/06 a } \\
\text { 01/07/14 }\end{array}$ & $8 \mathrm{~h}$ & $24 \mathrm{~h}$ & $x$ & $x$ & $x$ & $x$ & & \\
\hline 6 & $\begin{array}{l}02 / 07 \text { a } \\
15 / 07 / 14\end{array}$ & $8 \mathrm{~h}$ & $4 \mathrm{~h}$ & $x$ & $x$ & $x$ & $x$ & $x$ & \\
\hline 7 & $\begin{array}{l}16 / 07 \mathrm{a} \\
12 / 08 / 14\end{array}$ & $8 \mathrm{~h}$ & $8 \mathrm{~h}$ & $x$ & $x$ & $x$ & $x$ & $x$ & $x$ \\
\hline
\end{tabular}

descarte contínuo de lodo desde 0 até 24 horas. A fase 1 foi programada para um período de 58 dias contínuos, sem lançamento de lodo da ETA na ETE Verde. As fases 2 a 6 foram programadas para 14 dias contínuos de lançamento cada uma; e a fase 7 foi programada para um período de 28 dias contínuos de lançamento de lodo da ETA na ETE Verde.

A avaliação do processo de tratamento na ETE Verde foi feita a partir do monitoramento de dois parâmetros: a DQO total e SST. A evolução desses parâmetros foi acompanhada durante a operação normal da ETE, no período compreendido entre as sete fases da pesquisa. Também foi efetuado, nesse período, o registro da vazão média afluente à estação, obtida através de um medidor de nível ultrassônico, marca Nivetec, modelo SPE 390, instalado em vertedor Parshall existente no canal de entrada da ETE Verde.

Semanalmente, durante o período mencionado, foram retiradas amostras do afluente da estação de tratamento, do efluente dos reatores e do efluente da lagoa de polimento. Ao todo, foram coletadas 51 amostras de cada um dos 3 pontos indicados, e as análises dos parâmetros DQO e SST foram efetuadas em laboratório próprio da SANEPAR, na cidade de Ponta Grossa, Paraná, de acordo com o SMEWW (APHA; AWWA; WPCF, 1998).

A análise estatística dos dados obtidos em cada uma das sete fases do cronograma experimental foi realizada a partir das análises de variância pelo teste F; e a comparação das médias, com o teste de Tukey e o teste $t$ de Student, com nível de significância de $5 \%$.

\section{RESULTADOS E DISCUSSÃO}

Na Tabela 1 estão expressos os resultados encontrados para os parâmetros analisados na caracterização do lodo retirado da descarga dos decantadores da ETA Actiflo ${ }^{\circledR}$ e da ETA Pitangui, cujas amostras foram coletadas nos dias 08/01/13, 08/07/13 e 13/08/13.

Tabela 1 - Caracterização das amostras de lodo coletadas nas datas indicadas.

\begin{tabular}{|c|c|c|c|c|c|c|}
\hline \multirow{2}{*}{ Parâmetros } & \multicolumn{3}{|c|}{ ETA Actiflo ${ }^{\circledR}$} & \multicolumn{3}{|c|}{ ETA Pitangui } \\
\hline & 08/01/13 & $08 / 07 / 13$ & $13 / 08 / 13$ & $08 / 01 / 13$ & $08 / 07 / 13$ & $13 / 08 / 13$ \\
\hline $\mathrm{pH}$ & 6,72 & 6,88 & 6,80 & 6,88 & 6,67 & 6,72 \\
\hline $\mathrm{DQO}\left(\mathrm{mg} \cdot \mathrm{L}^{-1}\right)$ & 288 & 365 & 288 & 5.673 & 3.637 & 3.772 \\
\hline ST (\%) & 0,08 & 0,65 & 0,78 & 1,16 & 1,04 & 1,04 \\
\hline SF (\%) & 0,05 & 0,40 & 0,48 & 0,69 & 0,64 & 0,64 \\
\hline $\mathrm{SS}\left(\mathrm{mL} . \mathrm{L}^{-1}\right)$ & 100 & 800 & 800 & 900 & 800 & 900 \\
\hline CT (UFC.100 mL'ㄹ) & 13.500 & 10.900 & 10.500 & 4.000 & 8.300 & 9.440 \\
\hline $\mathrm{Al}\left(\mathrm{mg} \cdot \mathrm{L}^{-1}\right)$ & 50 & 8.649 & 3.530 & 420 & 6.879 & 7.243 \\
\hline $\mathrm{Fe}\left(\mathrm{mg} \cdot \mathrm{L}^{-1}\right)$ & 5 & 35.454 & 33.205 & 125 & 3.361 & 2.898 \\
\hline $\mathrm{Ba}, \mathrm{Cr}, \mathrm{Mo}\left(\mathrm{mg} . \mathrm{L}^{-1}\right)$ & $<5$ & $<5$ & $<5$ & $<5$ & $<5$ & $<5$ \\
\hline
\end{tabular}

ETA: estação de tratamento de água; DBO: demanda bioquímica de oxigênio; DQO: demanda química de oxigênio; ST: sólidos totais; SF: sólidos fixos; SV: sólidos voláteis; SS: sólidos sedimentáveis; CT: coliformes termotolerantes; UFC: unidades formadoras de colônias. 
As concentrações de matéria orgânica, de sólidos totais (ST), de sólidos fixos (SF) e de sólidos voláteis (SV) encontradas no lodo da ETA Actiflo ${ }^{\oplus}$ foram inferiores às encontradas no lodo da ETA Pitangui. Essa diferença deve-se principalmente ao regime de descarga dos decantadores: enquanto na ETA Pitangui os decantadores são paralisados para a limpeza e remoção manual do lodo a cada dois ou três dias, na ETA Actiflo ${ }^{\circledR}$ o lodo é removido continuamente, apresentando menores concentrações dos parâmetros mencionados.

Quanto ao teor de alumínio e ferro, observou-se uma variação acentuada entre os valores encontrados nas amostras coletadas no verão e no inverno. A causa mais provável para essa variação nos valores é a alteração na água bruta dos mananciais de abastecimento, principalmente na Represa Alagados, cuja água pode ser encaminhada para uma ou para a outra ETA, conforme a necessidade da operação da SANEPAR.
A medição de vazão do lodo da ETA Actiflo ${ }^{\circledR}$ resultou no valor médio de 7,00 L.s ${ }^{-1}$, com desvio padrão de 1,29 L.s ${ }^{-1}$. O maior valor encontrado foi de 11,50 L.s ${ }^{-1}$; e o menor valor foi de 4,25 L.s $\mathrm{s}^{-1}$, ambos obtidos no dia 25/03/14, com tempo chuvoso. Na Figura 1 são apresentados os valores correspondentes às 67 medições efetuadas.

Na Figura 2 são apresentados os valores correspondentes às 51 medições de vazão média diária afluente à ETE Verde, efetuadas no vertedor Parshall existente no canal de entrada da estação, durante as sete fases da pesquisa.

Para cada uma das sete fases foram efetuados os cálculos do volume diário total médio afluente à ETE Verde e do volume diário de lodo de ETA lançado na rede coletora, e obtida a respectiva relação percentual entre os dois volumes correspondentes (Tabela 2).

O lançamento do lodo da ETA Actiflo ${ }^{\circledast}$ na rede de esgotos não alterou a vazão média diária afluente à ETE Verde, visto que os resultados

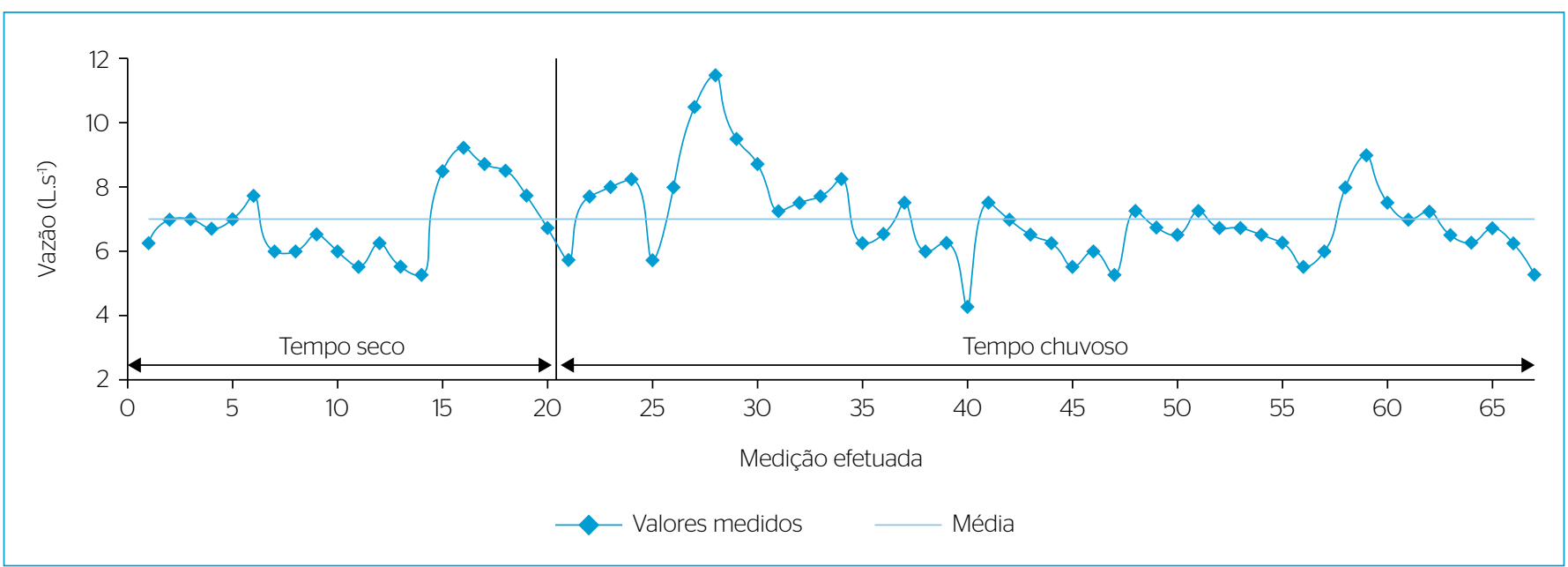

Figura 1 - Valores de vazão de descarte de lodo da estação de tratamento de água Actiflo ${ }^{\oplus}$.

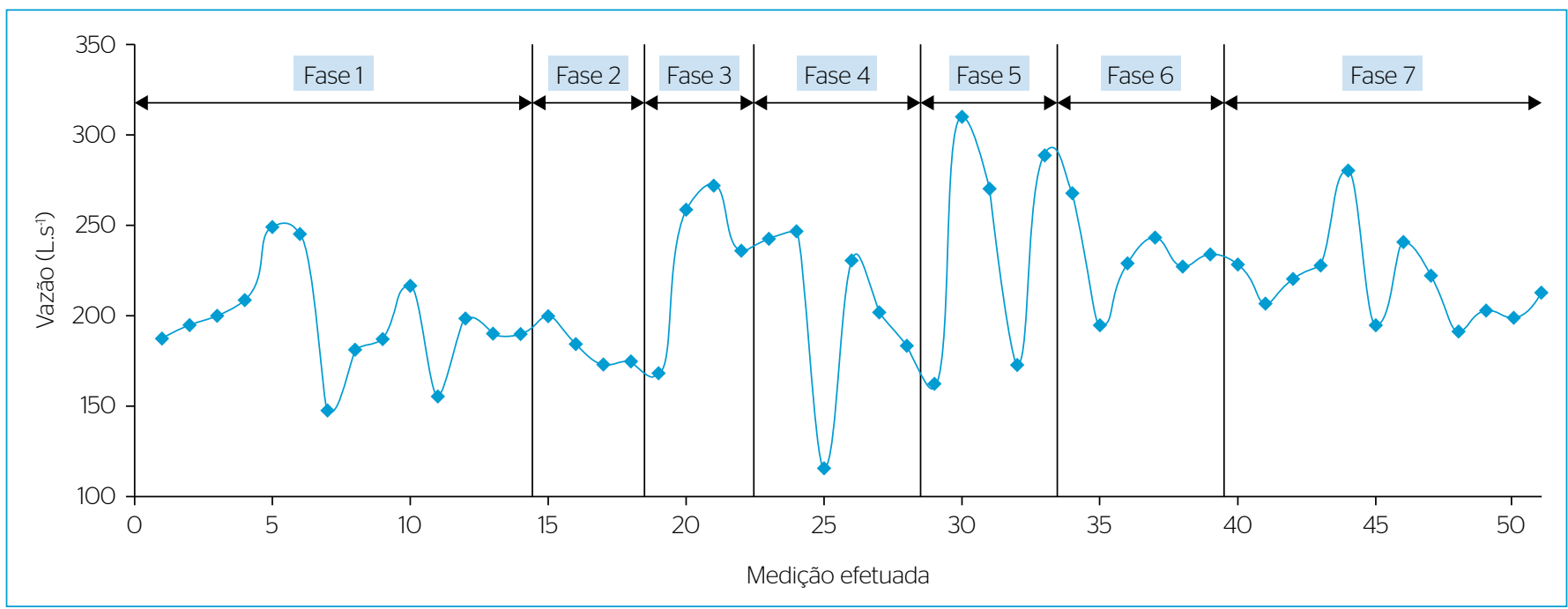

Figura 2 - Valores de vazão média diária afluente à estação de tratamento de esgoto Verde. 
das sete fases não diferiram estatisticamente entre si. Também não houve alteração no $\mathrm{pH}$ do afluente na entrada da ETA, o qual foi mantido variando na faixa entre 6,0 e 7,5.

Este resultado era esperado, visto que a vazão média de lodo descartado é pequena em relação à vazão média afluente à ETE $(3,2 \%$ em volume). Durante as 7 fases da pesquisa, os 4 RALFs operaram com vazão média inferior à de projeto $\left(280 \mathrm{~L} \cdot \mathrm{s}^{-1}\right)$.

A relação entre os volumes de lodo e de esgoto que chegam à ETE é um dos fatores preponderantes quanto aos resultados negativos que o lodo de ETA pode produzir no tratamento do esgoto (ASADA et al., 2010; DI BERNARDO; DANTAS; VOLTAN, 2012; MARGUTI; FERREIRA FILHO; PIVELI, 2018).

A proporção lodo/esgoto, em volume, utilizada nesta pesquisa, teve valor intermediário aos utilizados nas pesquisas desenvolvidas por Marguti, Ferreira Filho e Piveli (2018) e Ferreira Filho et al. (2013), cujos valores foram de 0,2 e $7 \%$, respectivamente.

$\mathrm{O} \mathrm{TDH}$ e a CHV aplicada resultaram nos valores apresentados na Tabela 3. Não houve alteração significativa desses valores nas unidades da ETE Verde com a aplicação do lodo da ETA Actiflo ${ }^{\circledR}$.

Os resultados de DQO média encontrados para o afluente, para o efluente dos reatores e para o efluente da lagoa da ETE Verde, relativos às 51 amostras coletadas, encontram-se apresentados na Tabela 4 . A variabilidade dos dados observados para o parâmetro DQO, relativo às 51 amostras coletadas, pode ser vista na Figura 3.

Tabela 2 - Volume médio diário de lodo descartado na rede de esgotos e volume diário total médio de esgotos afluente à estação de tratamento de esgoto Verde

\begin{tabular}{|c|c|c|c|c|c|c|}
\hline Fase & Período & \multicolumn{2}{|c|}{$\begin{array}{c}\text { Vazão média } \\
\text { diária afluente } \\
\text { à ETE (L.s.'s)* }\end{array}$} & $\begin{array}{l}\text { Volume } \\
\text { diário } \\
\text { total } \\
\text { médio } \\
\text { afluente } \\
\left(\mathrm{m}^{3}\right)\end{array}$ & $\begin{array}{c}\text { Volume } \\
\text { médio } \\
\text { diário } \\
\text { de lodo } \\
\text { descartado } \\
\left(\mathrm{m}^{3}\right)\end{array}$ & $\begin{array}{l}\text { Relação } \\
\text { entre } \\
\text { volume } \\
\text { de lodo e } \\
\text { volume } \\
\text { total (\%) }\end{array}$ \\
\hline 1 & $\begin{array}{c}\text { 10/03 a } \\
\text { 06/05/14 }\end{array}$ & 196,6 & a & $16.987,1$ & 0,0 & $0,0 \%$ \\
\hline 2 & $\begin{array}{c}07 / 05 \text { a } \\
20 / 05 / 14\end{array}$ & 182,9 & a & $15.802,6$ & 100,8 & $0,6 \%$ \\
\hline 3 & $\begin{array}{c}\text { 21/05 a } \\
\text { 03/06/14 }\end{array}$ & 233,7 & a & $20.195,4$ & 201,6 & $1,0 \%$ \\
\hline 4 & $\begin{array}{l}04 / 06 \text { a } \\
17 / 06 / 14\end{array}$ & 203,6 & a & $17.593,6$ & 302,4 & $1,7 \%$ \\
\hline 5 & $\begin{array}{l}\text { 18/06 a } \\
\text { 01/07/14 }\end{array}$ & 241,0 & a & $20.824,3$ & 403,2 & $1,9 \%$ \\
\hline 6 & $\begin{array}{l}02 / 07 \text { a } \\
15 / 07 / 14\end{array}$ & 232,8 & a & $20.110,6$ & 504,0 & $2,5 \%$ \\
\hline 7 & $\begin{array}{c}16 / 07 \text { a } \\
12 / 08 / 14\end{array}$ & 219,0 & a & $18.917,4$ & 604,8 & $3,2 \%$ \\
\hline
\end{tabular}

ETE: estação de tratamento de esgoto; *letras minúsculas diferentes diferem pelo teste de Tukey ao nível de significância de 5\%.
O valor de DQO média afluente à ETE encontrado é semelhante ao reportado em outras pesquisas em sistemas de esgotos operando em escala real (CARRARO, 2004; FERREIRA FILHO et al., 2013; MARGUTI; FERREIRA FILHO; PIVELI, 2018).

Foi observado que o lançamento do lodo da ETA somente produziu alterações significativas na DQO média afluente à ETE e na DQO média efluente dos reatores nos períodos de lançamento de 20 horas e de 24 horas contínuas (fases 6 e 7). As fases 2 a 5 apresentaram DQO média afluente à ETE e DQO média efluente dos RALFs com valores semelhantes aos encontrados no período em que a ETE recebeu apenas esgoto doméstico.

O incremento na DQO média afluente à ETE com o lançamento de lodo da ETA também foi observado nas pesquisas em escala real realizadas por Asada et al. (2010), Carraro (2004), Ferreira Filho et al. (2013) e Marguti, Ferreira Filho e Piveli (2018).

Tabela 3 - Valores de tempo de detenção hidráulica nos RALFs e na lagoa e valores de carga hidráulica volumétrica aplicada nos RALFs.

\begin{tabular}{|c|c|c|c|c|}
\hline \multirow{2}{*}{ Fase } & \multirow{2}{*}{ Período } & \multicolumn{2}{|c|}{ RALFs } & \multirow{2}{*}{$\begin{array}{l}\text { Lagoa } \\
\text { TDH (d) }\end{array}$} \\
\hline & & TDH (h) & $\mathrm{CHV}\left(\mathrm{m}^{3} \cdot \mathrm{m}^{-3} \cdot \mathrm{d}^{-1}\right)$ & \\
\hline 1 & 10/03 a 06/05/14 & 10,7 & 2,2 & 4,9 \\
\hline 2 & 07/05 a 20/05/14 & 11,5 & 2,1 & 5,3 \\
\hline 3 & 21/05 а 03/06/14 & 9,0 & 2,7 & 4,1 \\
\hline 4 & 04/06 a 17/06/14 & 10,4 & 2,3 & 4,7 \\
\hline 5 & 18/06 a 01/07/14 & 8,8 & 2,7 & 4,0 \\
\hline 6 & O2/07 a 15/07/14 & 9,1 & 2,6 & 4,1 \\
\hline 7 & 16/07 a 12/08/14 & 9,6 & 2,5 & 4,4 \\
\hline
\end{tabular}

TDH: tempo de detenção hidráulica; $\mathrm{CHV}$ : carga hidráulica volumétrica.

Tabela 4 - Demanda química de oxigênio média afluente, efluente dos RALFs e efluente da lagoa da estação de tratamento de esgoto Verde.

\begin{tabular}{|c|c|c|c|c|c|c|c|}
\hline \multirow{2}{*}{$\begin{array}{l}\text { Fase } \\
1\end{array}$} & \multirow{2}{*}{$\begin{array}{l}\text { Período } \\
\text { 10/03 a } \\
\text { 06/05/14 }\end{array}$} & \multicolumn{2}{|c|}{$\begin{array}{l}\text { DQO média } \\
\text { afluente à ETE } \\
\left(\mathrm{mg} \cdot \mathrm{L}^{-1}\right)^{*}\end{array}$} & \multicolumn{2}{|c|}{$\begin{array}{c}\text { DQO média } \\
\text { efluente dos } \\
\text { RALFs (mg.L-1)* }\end{array}$} & \multicolumn{2}{|c|}{$\begin{array}{l}\text { DQO média } \\
\text { efluente da } \\
\text { lagoa }\left(\mathrm{mg} \cdot \mathrm{L}^{-1}\right)^{*}\end{array}$} \\
\hline & & 335,6 & c & 93,6 & b & 58,1 & C \\
\hline 2 & $\begin{array}{c}07 / 05 \text { a } \\
\text { 20/05/14 }\end{array}$ & 468,8 & $a b c$ & 191,3 & $a b$ & 94,8 & $a b$ \\
\hline 3 & $\begin{array}{c}\text { 21/05 a } \\
\text { 03/06/14 }\end{array}$ & 367,0 & c & 184,3 & $a b$ & 71,5 & bc \\
\hline 4 & $\begin{array}{l}04 / 06 \text { a } \\
17 / 06 / 14\end{array}$ & 329,0 & c & 175,7 & $a b$ & 44,5 & c \\
\hline 5 & $\begin{array}{l}\text { 18/06 a } \\
\text { 01/07/14 }\end{array}$ & 460,0 & bc & 197,6 & $a b$ & 71,6 & bc \\
\hline 6 & $\begin{array}{l}\text { O2/O7 a } \\
15 / 07 / 14\end{array}$ & 625,3 & $a b$ & 297,0 & a & 104,0 & $a b$ \\
\hline 7 & $\begin{array}{c}16 / 07 \text { a } \\
12 / 08 / 14\end{array}$ & 668,2 & a & 293,4 & a & 121,3 & a \\
\hline
\end{tabular}

DQO: demanda química de oxigênio; ETE: estação de tratamento de esgoto; *letras minúsculas diferentes diferem pelo teste de Tukey ao nível de significância de $5 \%$. 
Esse incremento na DQO média afluente era esperado, em função das características do lodo descartado na ETA Actiflo ${ }^{\circledR}$ (conforme Tabela 1). O lodo de ETA é caracterizado por possuir sais de ferro ou de alumínio, provenientes dos coagulantes utilizados comumente nas ETAs, além da matéria orgânica e inorgânica, que justificam seu valor típico de DQO (NAIR; AHAMMED, 2015; SHARMA; THORNBERG; ANDERSEN, 2013).

Para a DQO média efluente da lagoa, as fases 3, 4 e 5 apresentaram resultados que não diferem estatisticamente do resultado encontrado na fase 1, enquanto as fases 2, 6 e 7 apresentaram resultados superiores ao da fase 1 .

Um aumento na DQO do efluente final com a introdução de lodo de ETA também foi observado nas pesquisas realizadas por Asada

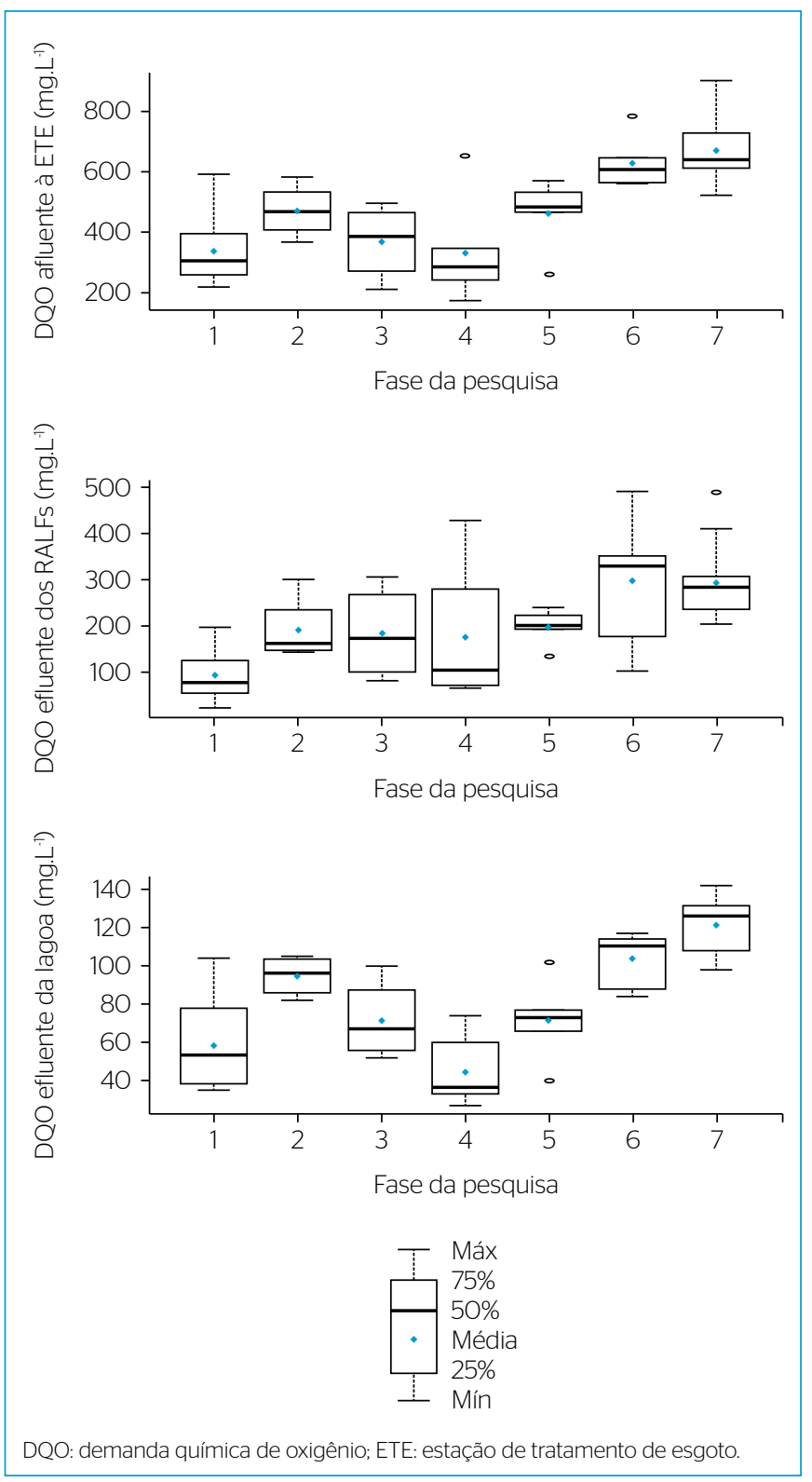

Figura 3 - Demanda química de oxigênio afluente, efluente dos RALFs e efluente da lagoa da estação de tratamento de esgoto Verde. et al. (2010) e Carraro (2004). Já nas pesquisas realizadas por Ferreira Filho et al. (2013) e Marguti, Ferreira Filho e Piveli (2018), não foram observadas mudanças significativas na DQO medida no efluente final.

Salienta-se que, embora a DQO média efluente à ETE Verde tenha sofrido acréscimo com o lançamento do lodo da ETA Actiflo ${ }^{\circledast}$, os valores apresentados não ultrapassaram os limites estabelecidos para o lançamento do efluente no Rio Verde.

Considerando-se os dados obtidos para a vazão média (Tabela 2) e os dados de DQO média afluente à ETE, efluente dos RALFs e efluente da lagoa de polimento (Tabela 4), foram calculados os valores de COV média aplicada nos RALFs, e os valores de TAS e COV média aplicada na lagoa de polimento, os quais estão apresentados na Tabela 5.

Na pesquisa realizada por Carraro (2004), foi encontrado para a COV aplicada no RALF monitorado da ETE Sul, em Londrina, Paraná, o valor médio de $0,60 \mathrm{kgDQO} \cdot \mathrm{m}^{-3} \cdot \mathrm{d}^{-1}$, nos períodos em que a ETE recebeu o lodo da ETA Cafezal, localizada no mesmo município.

Da Cruz (2013) pesquisou o acúmulo de lodo nas lagoas de estabilização do sistema de esgotamento sanitário do município de Ponta Grossa, e encontrou os valores de $884 \mathrm{kgDQO} \cdot \mathrm{ha}^{-1} \cdot \mathrm{d}^{-1}$ para a TAS e de 14 gDQO. $\mathrm{m}^{-3} \cdot \mathrm{d}^{-1}$ para a COV aplicada na lagoa de polimento da ETE Verde. Esses valores são bastante semelhantes aos valores encontrados nesta pesquisa para a fase 1 (sem lançamento do lodo da ETA).

Quanto aos SST, os resultados médios encontrados para o afluente, para o efluente dos reatores e para o efluente da lagoa da ETE Verde, relativos às 51 amostras coletadas, encontram-se apresentados na Tabela 6. A Figura 4 mostra a variabilidade dos resultados obtidos para as 51 amostras coletadas, relativos aos valores do parâmetro SST.

Tabela 5 - Valores de carga orgânica volumétrica aplicada nos RALFs e valores de taxa de aplicação superficial e carga orgânica volumétrica aplicadas na lagoa.

\begin{tabular}{|c|c|c|c|c|}
\hline \multirow[b]{2}{*}{ Fase } & \multirow[b]{2}{*}{ Período } & \multirow{2}{*}{$\begin{array}{c}\text { RALFs } \\
\text { COV } \\
\left(\mathrm{kgDQO} \cdot \mathrm{m}^{-3} \cdot \mathrm{d}^{-1}\right)\end{array}$} & \multicolumn{2}{|c|}{ Lagoa de polimento } \\
\hline & & & $\begin{array}{c}\text { TAS } \\
\left(\mathrm{kgDQO} \cdot \mathrm{ha}^{-1} \cdot \mathrm{d}^{-1}\right)\end{array}$ & $\begin{array}{c}\text { COV } \\
\left(\mathrm{gDQO} \cdot \mathrm{m}^{-3} \cdot \mathrm{d}^{-1}\right)\end{array}$ \\
\hline 1 & $\begin{array}{l}\text { 10/03 a } \\
\text { 06/05/14 }\end{array}$ & 0,75 & 765 & 19 \\
\hline 2 & $\begin{array}{c}\text { 07/05 a } \\
20 / 05 / 14\end{array}$ & 0,97 & 1.453 & 36 \\
\hline 3 & $\begin{array}{c}\text { 21/05 a } \\
\text { 03/06/14 }\end{array}$ & 0,98 & 1.789 & 45 \\
\hline 4 & $\begin{array}{l}\text { 04/06 a } \\
17 / 06 / 14\end{array}$ & 0,76 & 1.486 & 37 \\
\hline 5 & $\begin{array}{l}\text { 18/06 a } \\
\text { 01/07/14 }\end{array}$ & 1,26 & 1.978 & 49 \\
\hline 6 & $\begin{array}{l}\text { 02/07 a } \\
15 / 07 / 14\end{array}$ & 1,65 & 2.872 & 72 \\
\hline 7 & $\begin{array}{c}16 / 07 a \\
12 / 08 / 14\end{array}$ & 1,66 & 2.669 & 67 \\
\hline
\end{tabular}

COV: carga orgânica volumétrica; DQO: demanda química de oxigênio; TAS: taxa de aplicação superficial. 
Para o valor de SST afluente à ETE Verde, as fases 1 a 5 apresentaram resultados médios que não diferiram entre si. $\mathrm{O}$ mesmo ocorre com os resultados obtidos nas fases 2 a 7 . Assim sendo, foi observado que o lançamento do lodo da ETA só produziu alterações significativas no valor de SST afluente à estação nos períodos de 20 e 24 horas (fases 6 e 7).

O aumento na concentração de SST afluente com a adição de lodo de ETA também foi verificado nas pesquisas em sistemas de esgotos em escala real realizadas por Asada et al. (2010), Carraro (2004), Ferreira Filho et al. (2013) e Marguti, Ferreira Filho e Piveli (2018).

Maior acúmulo de sólidos no interior dos reatores e na lagoa de polimento da ETE Verde pode ser esperado em função do aumento de SST afluente a essas unidades. A operação do sistema deverá se programar para efetuar descargas de lodo nos reatores e dragagem da lagoa com maior frequência. Esse foi o principal efeito adverso verificado na pesquisa de Ferreira Filho et al. (2013), estudando uma lagoa de estabilização recebendo lodo de ETA.

Quanto ao valor de SST encontrado no efluente dos RALFs, observou-se que o lançamento do lodo da ETA produziu alterações significativas somente nos resultados nos períodos de 16 a 24 horas contínuas de lançamento (fases 5 a 7).

Para o valor de SST medido no efluente da lagoa da ETE Verde, os dados mostram que o lançamento do lodo da ETA Actiflo ${ }^{\circledR}$ na rede de esgotos produziu alterações significativas no valor de SST médio efluente da lagoa de polimento somente quando ocorreu o período de lançamento de 24 horas contínuas (fase 7).

A ocorrência do aumento da concentração de SST no efluente dos reatores recebendo lodo de ETA também foi verificada nas pesquisas realizadas por Asada et al. (2010) e Carraro (2004). No estudo realizado por

Tabela 6 - Sólidos suspensos totais médio afluente, efluente dos RALFs e efluente da lagoa da estação de tratamento de esgoto Verde.

\begin{tabular}{|c|c|c|c|c|c|c|c|}
\hline \multirow{2}{*}{$\begin{array}{c}\text { Fase } \\
1\end{array}$} & \multirow{2}{*}{$\begin{array}{l}\text { Período } \\
\text { 10/03 a } \\
\text { 06/05/14 }\end{array}$} & \multicolumn{2}{|c|}{$\begin{array}{l}\text { SST médio } \\
\text { afluente à ETE } \\
\left(\mathrm{mg} \cdot \mathrm{L}^{-1}\right)^{*}\end{array}$} & \multicolumn{2}{|c|}{$\begin{array}{c}\text { SST médio } \\
\text { efluente dos } \\
\left.\text { RALFs (mg. } \mathrm{L}^{-1}\right)^{*}\end{array}$} & \multicolumn{2}{|c|}{$\begin{array}{c}\text { SST médio } \\
\text { efluente da } \\
\text { lagoa }\left(\mathrm{mg} \cdot \mathrm{L}^{-1}\right)^{*}\end{array}$} \\
\hline & & 97,2 & b & 24,2 & $b$ & 7,0 & $b$ \\
\hline 2 & $\begin{array}{c}07 / 05 \text { a } \\
20 / 05 / 14\end{array}$ & 190,1 & $a b$ & 67,4 & $a b$ & 10,3 & $a b$ \\
\hline 3 & $\begin{array}{c}\text { 21/05 a } \\
\text { 03/06/14 }\end{array}$ & 145,9 & $a b$ & 92,4 & $a b$ & 9,5 & $a b$ \\
\hline 4 & $\begin{array}{l}\text { 04/06 a } \\
17 / 06 / 14\end{array}$ & 134,0 & $a b$ & 57,2 & $a b$ & 5,7 & $a b$ \\
\hline 5 & $\begin{array}{l}\text { 18/06 a } \\
\text { 01/07/14 }\end{array}$ & 190,5 & $a b$ & 120,8 & a & 14,5 & $a b$ \\
\hline 6 & $\begin{array}{l}\text { 02/07 a } \\
15 / 07 / 14\end{array}$ & 245,5 & a & 141,4 & a & 12,7 & $a b$ \\
\hline 7 & $\begin{array}{c}16 / 07 a \\
12 / 08 / 14\end{array}$ & 216,2 & a & 93,2 & a & 15,4 & a \\
\hline
\end{tabular}

SST: sólidos suspensos totais; ETE: estação de tratamento de esgoto; *letras minúsculas diferentes diferem pelo teste de Tukey ao nível de significância de 5\%.
Marguti, Ferreira Filho e Piveli (2018), foram verificados aumento no valor de SST no efluente do decantador primário e uma pequena redução no valor de SST do efluente final da ETE de lodos ativados recebendo a adição de lodo de ETA.

As eficiências na remoção de DQO e SST pelos RALFs e pela lagoa foram calculadas para cada uma das 51 amostras coletadas, e resultaram em valores médios para cada uma das 7 fases da pesquisa, conforme é apresentado na Tabela 7.

Os resultados encontrados para a eficiência média na remoção DQO e de SST pelos RALFs e para a eficiência média na remoção de SST pela lagoa não diferiram entre as sete fases da pesquisa. Para a DQO removida pela lagoa de polimento, os resultados apresentados

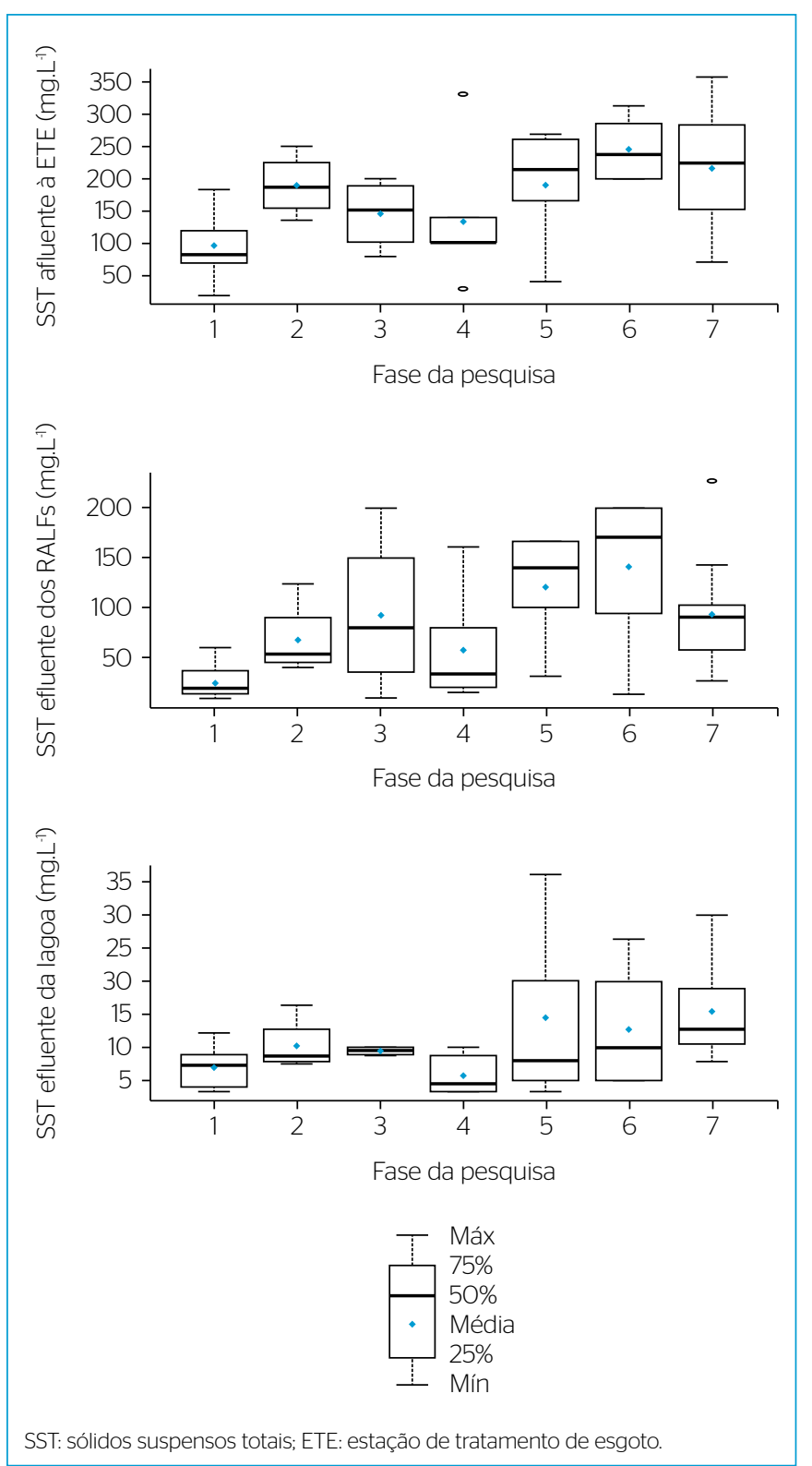

Figura 4 - Sólidos suspensos totais afluente, efluente dos RALFs e efluente da lagoa da estação de tratamento de esgoto Verde. 
nas fases 2 a 7 não diferiram entre si; e os resultados encontrados nas fases 4,5 e 7 foram superiores ao da fase 1, quando comparados pelo teste $t$ de Student ao nível de significância de 5\%.

Desta forma, observou-se que o lançamento do lodo da ETA Actiflo ${ }^{\circledR}$ na rede de esgotos não diminuiu a eficiência na remoção de DQO e SST, nem pelos RALFs, nem pela lagoa da ETE Verde, durante a realização da pesquisa, conforme observa-se na Tabela 8 .

Esse resultado tem sido observado em outras pesquisas semelhantes, em que o lançamento de lodo de ETA em sistemas de esgotos não tem produzido efeitos negativos na eficiência de tratamento, ao contrário, em alguns casos têm-se verificado melhora na eficiência de remoção de carga orgânica, sólidos e fósforo (ASADA et al., 2010;

Tabela 7 - Eficiência na remoção de demanda química de oxigênio e sólidos suspensos totais pelos RALFs e pela lagoa de polimento.

\begin{tabular}{|c|c|c|c|c|c|c|c|c|c|}
\hline \multirow{2}{*}{ Fase } & \multirow{2}{*}{ Período } & \multicolumn{4}{|c|}{ Eficiência dos RALFs (\%) } & \multicolumn{4}{|c|}{ Eficiência da lagoa (\%) } \\
\hline & & DQO & * & SST & $*$ & DQO & * & SST & * \\
\hline 1 & $\begin{array}{l}\text { 10/03 a } \\
\text { 06/05/14 }\end{array}$ & 72 & a & 72 & a & 29 & $b$ & 67 & a \\
\hline 2 & $\begin{array}{c}07 / 05 \text { a } \\
\text { 20/05/14 }\end{array}$ & 60 & a & 65 & a & 47 & $a b$ & 84 & a \\
\hline 3 & $\begin{array}{c}\text { 21/05 a } \\
\text { 03/06/14 }\end{array}$ & 49 & a & 44 & a & 55 & $a b$ & 69 & a \\
\hline 4 & $\begin{array}{l}04 / 06 \text { a } \\
17 / 06 / 14\end{array}$ & 41 & a & 32 & a & 64 & a & 83 & a \\
\hline 5 & $\begin{array}{l}18 / 06 \text { a } \\
\text { 01/07/14 }\end{array}$ & 56 & a & 35 & a & 64 & a & 89 & a \\
\hline 6 & $\begin{array}{l}02 / 07 \text { a } \\
15 / 07 / 14\end{array}$ & 53 & a & 39 & a & 57 & $a b$ & 86 & a \\
\hline 7 & $\begin{array}{c}16 / 07 \text { a } \\
12 / 08 / 14\end{array}$ & 56 & a & 52 & a & 56 & a & 79 & $a$ \\
\hline
\end{tabular}

DQO: demanda química de oxigênio; SST: sólidos suspensos totais; *letras minúsculas diferentes diferem pelo teste de Tukey ao nível de significância de 5\%.

Tabela 8 - Remoção média de demanda química de oxigênio e sólidos suspensos totais na estação de tratamento de esgoto Verde para as sete fases da pesquisa.

\begin{tabular}{|c|c|c|c|c|c|c|}
\hline Fase & $\begin{array}{l}\text { DQO } \\
\text { média } \\
\text { afluente } \\
\text { à ETE } \\
\left(\mathrm{mg} \cdot \mathrm{L}^{-1}\right)\end{array}$ & $\begin{array}{l}\text { DQO } \\
\text { média } \\
\text { efluente } \\
\text { da ETE } \\
\left(\mathrm{mg} \cdot \mathrm{L}^{-1}\right)\end{array}$ & $\begin{array}{c}\text { Remoção } \\
\text { de DQO } \\
\text { global da } \\
\text { ETE (\%) }\end{array}$ & $\begin{array}{l}\text { SST } \\
\text { médio } \\
\text { afluente } \\
\text { à ETE } \\
\left(\mathrm{mg} \cdot \mathrm{L}^{-1}\right)\end{array}$ & $\begin{array}{c}\text { SST } \\
\text { médio } \\
\text { efluente } \\
\text { da ETE } \\
\left(\mathrm{mg} \cdot \mathrm{L}^{-1}\right)\end{array}$ & $\begin{array}{c}\text { Remoção } \\
\text { de SST } \\
\text { global da } \\
\text { ETE (\%) }\end{array}$ \\
\hline 1 & 335,6 & 58,1 & 83 & 97,2 & 7,0 & 93 \\
\hline 2 & 468,8 & 94,8 & 80 & 190,1 & 10,3 & 95 \\
\hline 3 & 367,0 & 71,5 & 81 & 145,9 & 9,5 & 93 \\
\hline 4 & 329,0 & 44,5 & 86 & 134,0 & 5,7 & 96 \\
\hline 5 & 460,0 & 71,6 & 84 & 190,5 & 14,5 & 92 \\
\hline 6 & 625,3 & 104,0 & 83 & 245,5 & 12,7 & 95 \\
\hline 7 & 668,2 & 121,3 & 82 & 216,2 & 15,4 & 93 \\
\hline
\end{tabular}

DQO: demanda química de oxigênio; ETE: estação de tratamento de esgoto; SST: sólidos suspensos totais.
NAIR; AHAMMED, 2015; FERREIRA FILHO et al., 2013; MARGUTI; FERREIRA FILHO; PIVELI, 2018), o que reforça a tese de que o lançamento de lodo de ETA em ETE pode ser uma alternativa viável de disposição sob determinadas condições controladas.

\section{CONCLUSÃO}

O processo de tratamento de esgotos na ETE Verde manteve-se estável durante todo o período da pesquisa, operando com uma vazão média afluente de 213,14 L.s ${ }^{-1}$, mesmo durante os períodos em que recebeu o lançamento simultâneo do lodo da ETA Actiflo ${ }^{\circledR}$ na rede de esgotos, com vazão média de 7,00 L.s ${ }^{-1}$, que chegou a ocorrer durante 24 horas por dia, correspondendo ao percentual de 3,2\% do total afluente, em volume.

Os RALFs operaram com TDH médio de 9,9 horas e sua eficiência média na remoção de DQO variou entre 41 e $72 \%$. A lagoa de polimento operou com TDH médio de 4,5 dias e a sua eficiência na remoção de DQO variou entre 29 e 64\%. A remoção global de DQO pela ETE Verde variou entre 80 e $86 \%$.

Tanto para os RALFs quanto para a lagoa de polimento, aumento significativo na DQO efluente foi percebido somente quando a ETE operou com o lançamento simultâneo do lodo da ETA Actiflo ${ }^{\circledast}$ durante 20 e 24 horas por dia.

Porém, os RALFs não apresentaram variação significativa na eficiência média de remoção de DQO com o lançamento do lodo da ETA. Já a lagoa de polimento apresentou melhora na eficiência média na remoção de DQO com lançamento de lodo de ETA.

Com relação aos SST, os RALFs operaram com eficiência média de remoção variando entre 32 e $72 \%$. A lagoa de polimento operou com eficiência média na remoção de SST variando entre 67 e $89 \%$. A remoção global de SST pela ETE Verde variou entre 92 e 96\%.

A concentração média de SST efluente dos RALFs apresentou aumento significativo para lançamentos de lodo de ETA a partir de 16 horas por dia e somente com 24 horas por dia para o efluente da lagoa. Porém, a eficiência na remoção de SST foi mantida, tanto para os RALFs quanto para a lagoa de polimento da ETE Verde, mesmo com o lançamento simultâneo do lodo da ETA Actiflo ${ }^{\circledR}$.

De acordo com o resultado apresentado, conclui-se que o lançamento do lodo na rede de esgotos é uma alternativa viável de disposição para os rejeitos do decantador da ETA Actiflo ${ }^{\circledR}$, mesmo com duração de 24 horas por dia, não inviabilizando o tratamento de esgotos na ETE Verde. A SANEPAR continuou com o descarte do lodo da ETA Actiflo $^{\circledR}$ na rede coletora de esgotos, após a realização desta pesquisa.

\section{FONTE DE FINANCIAMENTO}

Companhia de Saneamento do Paraná (SANEPAR). 


\section{REFERÊNCIAS}

ACHON, C.L.; BARROSO, M.M.; CORDEIRO, J.S. (2013) Resíduos de estações de tratamento de água ea ISO 24512: desafio do saneamento brasileiro. Engenharia Sanitária e Ambiental, Rio de Janeiro, v. 18, n. 2, p. 115-122. http://dx.doi.org/10.1590/S1413-41522013000200003

AMERICANPUBLICHEALTHASSOCIATION(APHA);AMERICANWATER WORKS ASSOCIATION (AWWA); WATER POLLUTION CONTROL FEDERATION (WPCF). (1998) Standard Methods for the Examination of Water and Wastewater. 20. ed. Washington, D.C.: APHA. 1.569 p.

ASADA, L.N.; SUNDEFELD JUNIOR, G.C.; ALVAREZ, C.R.; FERREIRA FILHO, S.S.; PIVELI, R.P. (2010) Water treatment plant sludge discharge to wastewater treatment works: effects on the operation of upflow anaerobic sludge blanket reactor and activated sludge systems. Water Environment Research, v. 82, n. 5, p. 392-400. http:// dx.doi.org/10.2175/106143009X12487095236838

ASSOCIAÇÃO BRASILEIRA DE NORMAS TÉCNICAS (ABNT). (2004) NBR 10004: Resíduos sólidos - Classificação. Rio de Janeiro: ABNT.

BITTENCOURT, S.; SERRAT, B.M.; AISSE, M.M.; SOUZA MARIN, L.M.K.; SIMÃO, C.C. (2012) Aplicação de lodos de estações de tratamento deágua e de tratamento de esgoto em solo degradado. Engenharia Sanitária e Ambiental, Rio de Janeiro, v. 17, n. 3, p. 315-324. http:// dx.doi.org/10.1590/S1413-41522012000300008

CARNEIRO, C.; ANDREOLI, C. V. (2013) Lodo de estações de tratamento de água: Gestão e perspectivas tecnológicas. Curitiba: SANEPAR, Thinks Creative. 654 p.

CARRARO, A. (2004) Tecnologia ambiental apropriada a regiões de clima subtropical: avaliação do pós-tratamento de efluente RALF, através de filtro biológico aeróbio convencional, com recebimento intermitente de lodo de ETA. 262f. Dissertação (Mestrado em Geografia, Desenvolvimento e Meio Ambiente) - Universidade Estadual de Londrina, Londrina.

DA CRUZ, G.J.G. (2013) O acúmulo de lodo em lagoas de estabilização no tratamento de esgoto sanitário doméstico: estudo de caso das lagoas do município de Ponta Grossa, Paraná. 86f. Dissertação (Mestrado em Meio Ambiente Urbano e Industrial) Universidade Federal do Paraná, Curitiba.

DI BERNARDO, L.; DANTAS, A.B.; VOLTAN, P.E.N. (2012) Métodos e técnicas de tratamento e disposição dos resíduos gerados em estações de tratamento de água. São Paulo: LDiBe. 540 p.
FERREIRA FILHO, S.S.; PIVELI, R.P.; CUTOLO, S.A.; OLIVEIRA, A.A. (2013) Water treatment plant sludge disposal into stabilization ponds. Water Science and Technology, v. 67, n. 5, p. 1017-1025 https://doi.org/10.2166/wst.2013.652

JANUÁRIO, G.F.; FERREIRA FILHO, S.S. (2007) Planejamento e aspectos ambientais envolvidos na disposição final de lodos das estações de tratamento de água da região metropolitana de São Paulo. Engenharia Sanitária e Ambiental, Rio de Janeiro, v. 12, n. 2, p. 117-126. http://dx.doi.org/10.1590/S1413-41522007000200002

MARGUTI, A.L.; FERREIRA FILHO, S.S.; PIVELI, R.P. (2O18) Full-scale effects of addition of sludge from water treatment stations into processes of sewage treatment by conventional activated sludge. Journal of Environmental Management, v. 215, p. 283-293. http:// dx.doi.org/10.1016/j.jenvman.2018.03.072

NAIR, A.T.; AHAMMED, M.M. (2015) The reuse of water treatment sludge as a coagulant for post-treatment of UASB reactor treating urban wastewater. Journal of Cleaner Production, v. 96, p. 272-281. http://dx.doi.org/10.1016/j.jclepro.2013.12.037

SANTOS, G.Z.B.; MELO FILHO, J.A.; MANZATO, L. (2018) Proposta de uma cerâmica obtida por meio de geopolimerização de lodo de ETA calcinado. Cerâmica, São Paulo, v. 64, n. 370, p. 276-283. http:// dx.doi.org/10.1590/0366-69132018643702353

SHARMA, A.K.; THORNBERG, D.; ANDERSEN, H.R. (2O13) Application of waterworks sludge in wastewater treatment plants. International Journal of Environmental Science and Technology, v. 10, n. 6 , p. 1157-1166. http://dx.doi.org/10.1007/s13762-013-0191-6

TAFAREL, N.F.; MACIOSKI, G.; CARVALHO, K.Q.; NAGALLI, A.; FREITAS, D.C.; PASSIG, F.H. (2O16) Avaliação das propriedades do concreto devido à incorporação de lodo de estação de tratamento de água. Matéria, Rio de Janeiro, v. 21, n. 4, p. 974-986. http://dx.doi. org/10.1590/s1517-707620160004.0090

UNITED STATES ENVIRONMENTAL PROTECTION AGENCY (USEPA). (2003) Wastewater Technology Fact Sheet: Ballasted Flocculation. Washington, D.C.: USEPA. 8 p.

WOLFF, E.; SCHWABE, W.K.; CONCEIÇÃO, S.V. (2015) Utilization of water treatment plant sludge in structural ceramics. Journal of Cleaner Production, v. 96, p. 282-289. http://dx.doi.org/10.1016/j. jclepro.2014.06.018 